\title{
Maximum Crack Width Prediction in Deck Slab Concrete Structure
}

\author{
Nawir Rasidi
}

\begin{abstract}
Inspection of crack width prediction procedures proposed by various researchers indicates that each formula contains a different set of variables. A literature review also suggests that there is no general agreement among various researchers on the relative significance of different variables affecting the crack width, despite the large number of experimental work carried out during the past few decades. An analytical method is developed to determine the concrete stress distribution near flexural cracks in reinforced concrete one-way slabs and used to investigate the effects of various variables on the spacing and width of cracks. The formula is developed using a large number of curvature values calculated from the concrete and steel strains at various sections between adjacent cracks for a number of composite precast deck slabs. The present method of incorporating the tension stiffening effect is verified by comparing calculated fracture mechanic and those measured by other investigators. The curvature values at sections between adjacent cracks are calculated using an empirical formula. Development of this formula is based on the curvature values calculated using the concrete and steel strains at various sections between successive cracks, for a number of composite precast deck slabs. Using the curvature values evaluated by the proposed formula, short-term deflections were determined for a large number of flexural members and the results were compared with those measured by other investigators. This comparison indicated that the present method of incorporating the tension stiffening effect in fracture mechanic calculations is acceptable.
\end{abstract}

Keywords— crack width, precast deck slab, composite structure, formula.

\section{INTRODUCTION}

C racking in reinforced concrete structures is unavoidable due to the low tensile strength of concrete. Wider cracks may not only destroy the aesthetics of the structure, but also expose steel reinforcement to the environment leading to corrosion. To control the crack width at the member surface, designers may use the guidelines prescribed in various building codes. These guidelines are based on certain crack width prediction formulas developed by various researchers.

Inspection of crack width prediction procedures proposed by various investigators indicates that each formula contains a different set of variables. A literature review also suggests that there is no general agreement among various investigators on the relative significance of different variables affecting the crack width, despite the large number of experimental work carried out during the past few decades. This is at least partly due to the differences in the variables incorporated by different investigators in their experimental work. Taking all the parameters in to account in a single experimental program is not normally feasible due to the large number of variables involved, and the interdependency of some of the variables. Analytical methods, on the other hand, can incorporate most of the variables without much difficulty. However, a literature search reveals that different investigators have concentrated on different sets of parameters in their calculation, to simplify the complex phenomenon of cracking in reinforced concrete. A major focus in this research is to incorporate as many parameters as possible in an analytical investigation.

Cracking in a reinforced concrete member also causes a significant increase in deflection. This is a result of the reduction of bending stiffness at cracked sections when the effect of tensile concrete below the neutral axis diminishes. However, at sections between successive cracks, some tensile stress is retained in the concrete around steel bars due to the action of bond, contributing to the bending stiffness of the member. This is called the "tension stiffening" effect. If the tension stiffening effect is neglected, the calculated defection may be overestimated by a large proportion. In simplified methods of deflection calculation, the tension stiffening effect is incorporated in a semi-empirical manner by using the effective moment of inertia method.

In analytical methods, the deflection is calculated using the curvature values, evaluated by adopting a non-linear stress-strain relationship for tensile concrete. This relationship allows the concrete to retain some tensile stress beyond the cracking strain. A new method is developed to evaluate the curvature values at sections between successive cracks by incorporating the bond force acting around steel bars in the calculation, instead of the concrete tensile force.

\section{A. Allowable crack widths in reinforced concrete}

An easy way to comply with the journal paper formatting requirements is to use this document as a template and simply type your text into it.

The maximum crack width that may be considered not to impair the appearance of a structure depends on various factors including the position, length, and surface texture of the crack as well as the illumination in the surrounding area. Crack widths in the range $0.25 \mathrm{~mm}$ to $0.38 \mathrm{~mm}$ may be acceptable for aesthetic reasons [20].

Crack width that will not endanger the corrosion of steel reinforcement depends on the environment surrounding the structure. Table 1 . shows the maximum allowable crack widths recommended by ACI Committee 224 [2] for the protection of reinforcement against corrosion. These values are taken as the basis for the development of rules prescribed in ACI 318 [3] for the distribution of tension steel to limit the crack width. 


\section{B. Causes of cracking}

Cracks formed in reinforced concrete members can be classified into two main categories, namely cracks caused by externally applied loads, and those which occur independently of the loads [14]. Flexural cracks and inclined shear cracks are the two main types of cracks caused by external loads. Flexural cracks are formed in the tensile zone of the member and have a wedge shape, with the maximum crack width at the tension face and zero width near the neutral axis. Inclined shear cracks usually develop in thin-web beams when subjected to high shear forces [14].

Internal micro-cracks fall into the other type of cracks caused by external load. These cracks occur as a result of high concrete stresses near the ribs in deformed bars, and are confined in the immediate neighbourhood of reinforcement without appearing on the concrete surface.

Cracks developed in restrained members due to concrete shrinkage or temperature change fall into the second category of cracks, which are independent of applied loads. In thin restrained members such as floor slabs these cracks may extend through the entire cross section, usually having an approximately uniform width. If the width of these cracks is not properly controlled, they may disrupt the integrity of the structure and reduce the bending stiffness considerably resulting in large deflections.

Flexural cracks begin to occur when concrete stress in the tension face of a member reaches the flexural strength of concrete. After formation of a crack some elastic recovery takes place in concrete on the member surface, contributing to the crack width. However, some stress and strain is maintained in concrete surrounding the reinforcement due to the action of bond. This contributes to a reduction in the crack width near the bar compared to that at the tension face [21].

Flexural cracks in a varying moment region of a beam develop at a regular interval; however, in a constant moment region, these cracks develop at discrete intervals. Their locations depend partly on the occurrence and distribution of zones of local weakness in concrete, and therefore cracking is somewhat a random process [21]. As a result, the exact locations of cracks in a constant moment region may not be predicted accurately. However, maximum and minimum spacing of adjacent cracks and the resulting maximum crack width may be predicted with sufficient accuracy by investigating concrete stresses developed in the tensile zone of a member.

\section{Predicting width of flexural crack}

The development of crack width (w) prediction formulas is usually based on calculated concrete stress distributions within the tensile zone of a member. Different investigators have used various simplified analytical procedures to determine the concrete tensile stress. While some analytical investigations are coupled with experimental works to verify the new prediction formulas, there are some investigations totally based on test results.

In most investigations, a uniaxial tension member has been used to simulate the conditions around steel bars in the constant moment region of a member. In experimental investigations, a concrete prism with a steel bar embedded along its axis is subjected to a tensile force applied to the two protruding ends of the bar. The resulting tensile cracks are considered to represent flexural cracks in a constant moment region of a beam. In analytical investigations the axial tensile stress distribution, developed in the concrete prism resulting from the bond force transferred from the steel bar, is calculated. This stress distribution is then used to predict the formation of new cracks in between existing cracks.

The literature review suggested that there is no general agreement among different investigators on the relative significance of various variables affecting the crack width, which sometimes leads to differing conclusions.

This is at least partly due to the absence of test data that describe the individual effects of each variable. Producing such a data set in the laboratory is expensive and time consuming because of the large number of variables involved, and due to the interdependency of some of the variables. A mathematical model capable of accurately predicting the spacing and width of cracks can be used to overcome this problem if it can include all variables involved in flexural cracking. This is not available at present, and is a main focus in this research.

\section{Precast Concrete Bridge Deck Panel System}

Precast bridge deck panels have been used for quite some time, however, an increase in the number of bridges undergoing reconstruction and rehabilitation has focused attention on the use of the fully precast system. A fully precast system can ensure quality and minimize hardship on the motoring public by minimizing construction related delays.

The construction of the bridge deck is the last component of bridge construction that requires refinement to achieve a fully functional totally prefabricated bridge system. Full-depth bridge deck panels have been developed and used extensively in Indonesia in the past decade.

Composite construction allows the designer to utilize the strength of the deck coupled with the girder to provide a more efficient and economical design. In order to account for this, the designer must accurately predict the horizontal shear developed at the interface between the slab and girder and provide adequate connectivity between the two to develop the full composite action.

\section{METHOD}

To examine the crack width of a precast bridge deck panel system on precast girders 18 deck slab composite load tests were conducted. Concrete stress distribution slightly along the length of the span due to the nonhomogeneity of concrete and due to the presence of micro-cracks that may have occurred before the application of loading. Since the cracking moment $\mathrm{Mcr}$ is proportional to the flexural strength of concrete $f r$, the possible variation of Mcr along the length of the slab is treated as a variation of $f r$ for convenience, in the following discussion. Consequently, it is assumed that a primary crack is formed when the calculated tensile stress frc at the tension face of the member reaches the flexural strength of concrete $\mathrm{fr}$.

patterns determined in formula are utilised in this experiment to predict the locations of cracks formed in a member when it is subjected to a gradually increasing load. Locations of primary cracks are determined based 
on the concrete stress distribution evaluated near the first flexural crack of the member. It is shown that the primary crack width in both constant and varying moment regions are governed by the slip length (bond length required to resist the steel stress increment at the first flexural crack). This prediction is verified by comparing the calculated and measured values of primary crack width in constant and varying moment regions.

The maximum crack width at a given load level is determined using the elastic extensions of steel and surrounding concrete. Using the present analytical procedure, the average maximum crack widths within constant moment regions are computed for 18 flexural members at various load levels.

The accuracy of the proposed calculation method is verified by comparing the calculated width of cracks with the measured values. When a member is subjected to a gradually increasing load, the first flexural crack is developed at the location where the applied bending moment is equal to the cracking moment. Even in a prismatic member, the cracking moment may vary.

\section{RESULT AND DISCUSSION}

Although many investigations have been carried out on cracking of reinforced concrete flexural members, results of individual crack width are rarely available; only the average crack widths are reported most of the times.

Agoes Soehardjono has reported the results of individual crack width for any various reinforcement on two simply supported slabs. These measurements are compared with the predictions made in the previous section on primary crack width in constant and varying moment regions.

Width of cracks in reinforced concrete members were determined using the calculated concrete stress distributions near flexural cracks. To calculate the stresses, a free body concrete block bounded by top and bottom faces and two transverse sections of the member was isolated and analysed using the spreadsheet.

An investigation in to the effects of various variables on the width of cracks revealed the following:

a. An increase in the width of the member or the concrete cover increases crack width if other variables are kept unchanged.

b. Concrete strength has no appreciable effect on the crack width, if other variables remain unchanged.

c. An increase in the number of bars, by reducing the bar diameter to have the same reinforcement ratio, will reduce width of cracks.

d. The steel stress at the cracked section will reduce the crack spacing while it increases the crack width.

Composite construction allows the designer to utilize the strength of the deck coupled with the precast panel to provide a more efficient and economical design. In order to account for this, the designer must accurately predict the horizontal shear developed at the interface between the topping slab and precast panel and provide adequate connectivity between the two to develop the full composite action.

\section{CONCLUSION}

Based on the results of a parametric study, simplified formulas were developed for the prediction of maximum crack width. A comparison of predicted crack widths for the flexural members and the measured values reveals that the proposed formulas perform adequately. In particular, the predictions of these formulas have almost the same accuracy as the results of the various investigators and various codes.

The proposed formula for precast deck slab composite is :

$\mathbf{w}_{\text {max }}=3,38.10^{-4} \frac{(1+0,07 . \mathrm{c})}{\left(1+\frac{16 . \mathrm{n} \cdot \overline{\mathrm{p}}}{3}\right)} \mathrm{p}$ fs $(\mathrm{mm})$

Where,

$$
\begin{array}{ll}
\mathrm{w}_{\max } & =\text { maximum crack width }(\mathrm{mm}) \\
\mathrm{C} & =\text { depth of concrete cover }(\mathrm{mm}) \\
\mathrm{n} & =\text { modular ratio of steel and concrete } \\
\overline{\boldsymbol{\rho}} & =\text { reinforcement ratio } \\
\mathrm{fs} & =\text { stress of steel reinforcement }(\mathrm{MPa}) \\
\mathrm{p} & =\text { precast modification factor }
\end{array}
$$

$p=\left(\frac{1}{1+\frac{E_{p} A_{p}}{E_{d} A_{d}}}\right)\left(\frac{1}{1+\frac{E_{s} A_{s}}{E_{d} A_{d}}}\right)$

$\mathrm{E}_{\mathrm{p}}=$ modulus of elasticity of the precast panels(MPa)

$\mathrm{A}_{\mathrm{p}}=$ area of precast panels $\left(\mathrm{mm}^{2}\right)$

$\mathrm{E}_{\mathrm{s}}=$ modulus of elasticity of steel reinforcement in topping deck (MPa)

$A_{s}=$ area of steel reinforcement in topping deck $\left(\mathrm{mm}^{2}\right)$

$\mathrm{E}_{\mathrm{d}} \quad=$ modulus of elasticity of topping deck (MPa)

$\mathrm{A}_{\mathrm{d}}$ = area of topping deck (MPa)

Analytical results of crack widths are greatly influenced by the assumed bond stress distribution and bond stress-bond slip relationship. The constitutive relationships proposed by different investigators vary considerably. Further research in to the measurement of bond stress and bond slip is proposed.

It was shown that the crack width increases with concrete cover. In spite of this, provision of a large cover is considered to be the most practical means of protecting the reinforcement against corrosion. Further research in to the effect of varying concrete cover on the crack width is proposed.

The proposed analytical procedure can also be extended to determine the increase in the crack width with time by incorporating the creep and shrinkage effects in the calculation of concrete and steel strains.

\section{ACKNOWLEDGEMENT}

The author would like to acknowledge the Indonesian Directorate General of Higher Education (DIKTI) for providing the $\mathrm{PhD}$ scholarship. The author would also like to acknowledge the employer, State Polytechnic of Malang for providing with support.

\section{REFERENCES}

[1]. AASHTO LRFD, "Bridge Design Specification”, Second Edition, American Association of State Highway and Transportation Officials, Washington D.C,1998. 
[2]. ACI Committee 224, "Control of Cracking in Concrete Structures”, ACI Journal, Proceedings, Vol. 69, No. 12, 1972.

[3]. ACI 318-89, "Building Code Requirements for Reinforced Concrete", 5th , PCA, Detroit, Michigan, 1990.

[4]. ACI Committee 318, "Building Code Requirements for Structural Concrete”,.Farmington Hills, 1995.

[5]. Al-Shaikh, A. H. and Al-Zaid, R. Z., "Effect of Reinforcement Ratio on the Effective Moment of Inertia of Reinforced Concrete Beams”, ACI Structural Journal, Vol. 90, No. 2, 1993.

[6]. Agoes Soehardjono MD, "The Influence of Reinforcement Ratio $(\square)$ and Repeated Loading (N) to Crack Width (w) of One Way Slab”, Dissertation, Civil Enginering ITS, Surabaya, Indonesia, 2006.

[7]. Barker, RM dan Puckett, JA, "Design of Highway Bridges Based On AASHTO LRFD”, John Wiley \& Sons Inc, New York, 1997.

[8]. Broek D, "The Practical Use of Fracture Mechanics", 2nd Edition, Kluwer Academic Publishers, London., 1989.

[9]. Callister, WD, Jr, "Material Science and Engineering an Introduction”, Fourth Edition, John Wiley \& Sons Inc, New York. , 1997.

[10]. Carpinteri, Alberto, "Applications of Fracture Mechanics to Reinforced Concrete”, Elsevier Applied Science, Turin, Italy, 1990.

[11]. Ellyn F, "Fatigue Damage, Crack Growth and Life Prediction", Chapman \& Hall, New York., 1997.

[12]. Esfahani, M. R. and Rangan, B. V, ”Local Bond Strength of Reinforcing Bars in Normal Strength and High-Strength Concrete (HSC) ”, ACI Structural Journal, Vol. 95, No. 2, 1998, pp 96 - 106
[13]. Giuriani, E. and Plizzari, G. A, "Interrelation of Splitting and Flexural Cracks in RC Beams, Journal of the Structural Engineering”, American Society of Civil Engineers, Vol. 124, No. 9,1998.

[14]. Joseph A. Wallenfelsz, "Horizontal Shear Transfer for fullDepth Precast Concrete Bridge Deck Panels", Master Thesis, Virginia Polytechnic Institute and State University., 2006.

[15]. Lan, Z. and Ding, D,"Crack Width in Reinforced Concrete Members”, International Journal of Structures, Vol. 12, No. 2, 1992.

[16]. New Zealand Standard 3101, "Code of Practice for The Design of Concrete Structures", Standard Association of New Zealand part 1, 1982

[17]. Oh, B. H. and Kang, Y., ”New Formulas for Maximum Crack Width and Crack Spacing in Reinforced Concrete Flexura Members”, ACI Structural Journal, Vol. 84, No. 2,1987.

[18]. Park, R., Kent, D. C., dan Sampson, R. A, ”Reinforced Concrete Members with Cyclic Loading, Journal of the Structural Division”, Proceeding of the ASCE, vol. 98, no. ST7,1972.

[19]. Park, R dan Gamble, W.L, ”Reinforced Concrete Slabs”, John Wiley \& Sons, Inc, A Wiley-Interscience Publication. , 1980

[20]. Park, R dan Paulay, T, Reinforced Concrete Structures, John Wiley \& Sons, Inc, Canada, USA. , 1975

[21]. Ratnamudigedara Piyasena, "Crack Spacing, Crack Width and tension Stiffening Effect in Reinforced Concrete Beams and One Way Slab”, Dissertation Doctor of Philosophy, Gold Coast Campus Griffith University. , 2002

[22]. Standards Australia (AS 3600), "Concrete Structures", Standards Association of Australia, Sydney, Australia2001.
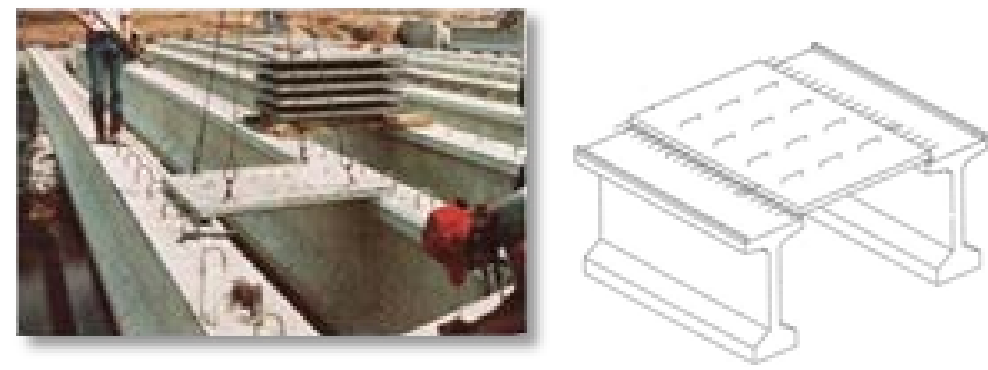

Figure. 1. Precast panel deck slab

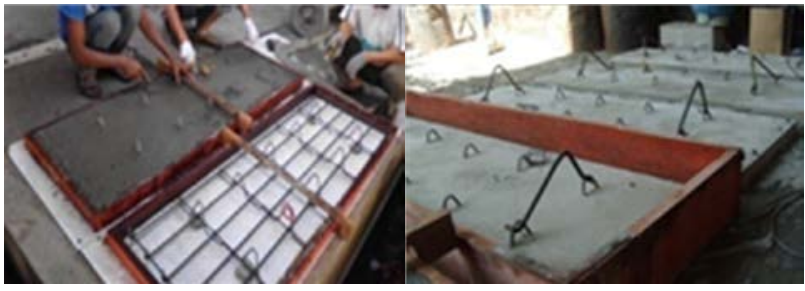

(a)

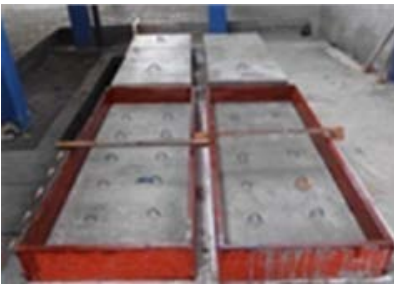

(c)

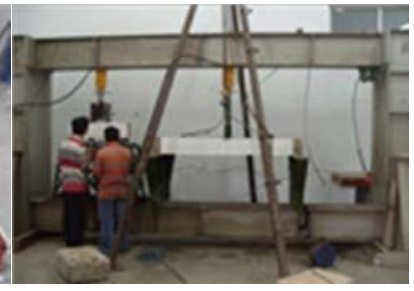

(d)

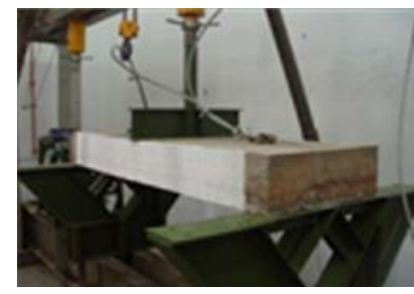

(e)

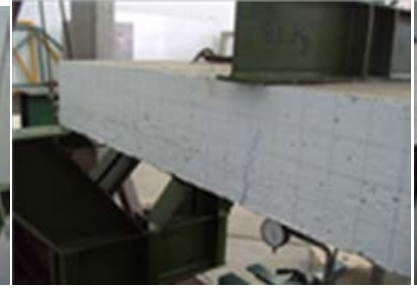

(f)

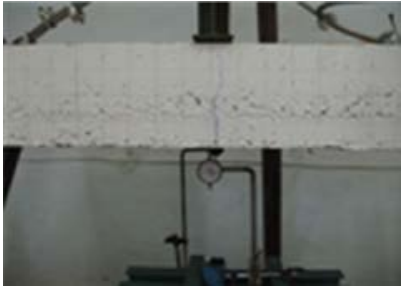

(g)

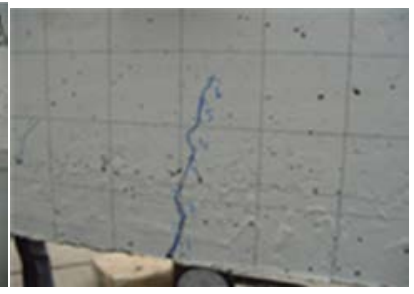

(h)

Figure. 2. Flexural test specimens

(a) steel reinforcement (b) shear connector (c) cast in place (d) setting up (e) knife load (f) crack detection (g) deflection and strain indicator (h) crack width 
Figure. 3. Variation of crack width with load for six types of reinforcement

Figure. 4. Variation of deflection with load for six types of reinforcement

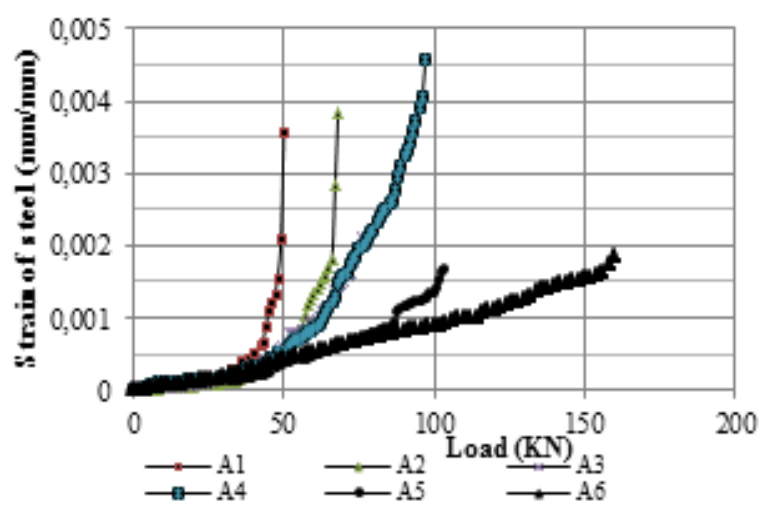

Figure. 5. Variation of deflection with load for six types of reinforcement

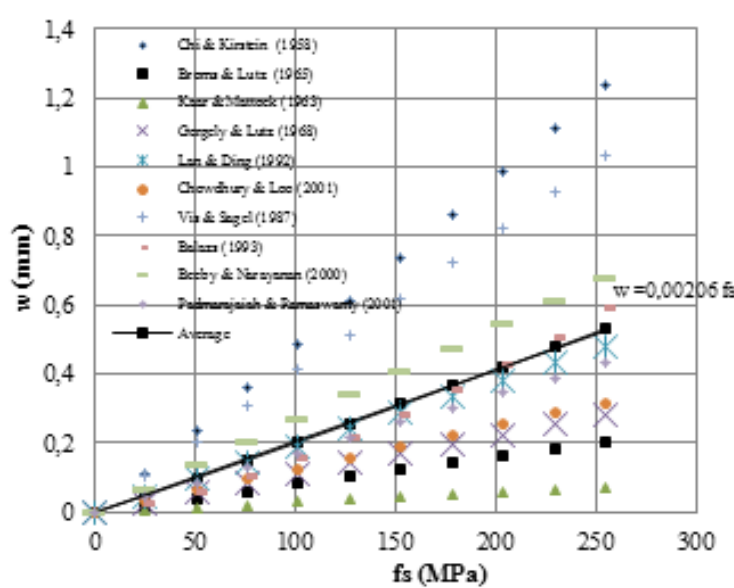

Figure. 6. Variation of crack width (w) calculation with stress of steel (fs) for various investigators

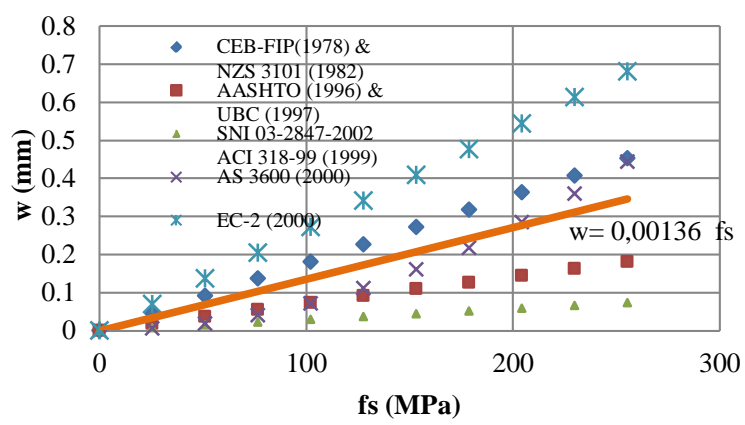

Figure. 7. Variation of crack width (w) calculation with stress of steel (fs) for various codes

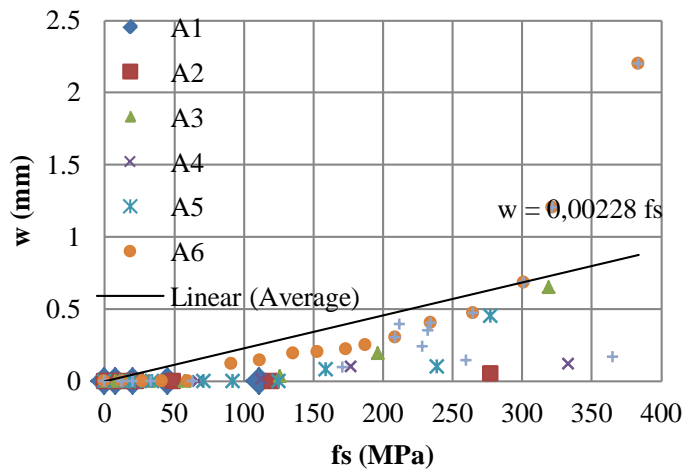

Figure. 8. Variation of crack width (w) calculation with stress of steel (fs) by experimental results 